\title{
Influence of abutment characteristics on marginal bone level changes in immediate loading implant-supported full-arch fixed dental prostheses: a retrospective case series study with 1-year follow-up
}

\author{
Juan Carlos Bernabeu-Mira, David Soto-Peñaloza, Miguel Peñarrocha-Diago, David Peñarrocha-Oltra \\ Oral Surgery Unit, Department of Stomatology, Faculty of Medicine and Dentistry, University of Valencia, Valencia, Spain \\ Contributions: (I) Conception and design: All authors; (II) Administrative support: D Peñarrocha-Oltra, M Peñarrocha-Diago; (III) Provision of study materials \\ or patients: D Peñarrocha-Oltra, M Peñarrocha-Diago; (IV) Collection and assembly of data: D Soto-Peñaloza; (V) Data analysis and interpretation: D \\ Peñarrocha-Oltra, D Soto-Peñaloza, JC Bernabeu-Mira; (VI) Manuscript writing: All authors; (VII) Final approval of manuscript: All authors. \\ Correspondence to: David Soto-Peñaloza, DDS, MSc, PhD. Master in Oral Surgery and Implant Dentistry, Department of Stomatology, Faculty of \\ Medicine and Dentistry (University of Valencia), Gascó Oliag, 1, 46010 Valencia, Spain. Email: dr.davidsotpe@gmail.com.
}

Background: The aim was to evaluate the influence of axial abutment height, abutment angulation, angulated abutment side and implant site on peri-implant marginal bone loss and marginal bone remodeling after 1 year of follow-up in immediate loading implant-supported full-arch fixed dental prostheses.

Methods: A retrospective analysis was conducted of patients treated with immediate loading implant-supported full-arch fixed dental prostheses. The retrieved data were: sex, age, implant number, implant length, abutment height, abutment angulation (axial or angulated), implant site (maxilla or mandibular), implant failure and periimplant marginal bone level changes. The marginal bone loss and marginal bone remodeling were evaluated after 6 and 12 months of functional loading trough orthopantomographies. The differences were calculated for axial abutment height (2 vs. $3 \mathrm{~mm}$ ), abutment angulation for the whole sample and specifically within $3 \mathrm{~mm}$ abutments (axial vs. angulated), angulated abutment side (mesial vs. distal) and implant site (maxilla or mandible). The t-test were used for statistical analysis, the level of significance $(\mathrm{P} \leq 0.05)$ was stablished.

Results: Seventeen patients (mean age, 65 years) with a total of 87 dental implants were included. No implant failed. The mean marginal bone loss was -0.24 [0.89 standard deviation (SD)] $\mathrm{mm}$ at 6 months and $-0.51(0.26 \mathrm{SD}) \mathrm{mm}$ at 12 months. No significant differences were observed in marginal bone changes neither between 2- and 3-mm axial abutments nor between axial and angulated abutment. Marginal bone changes were higher in 2-mm axial abutments than in 3-mm ones, in angulated abutment than in axial ones, and in mesial sites of angulated abutments than distal sites, but all these differences were non-significant. Considering only 3-mm high abutments, significantly higher marginal bone loss was detected after 12 months and more bone remodeling after 6 months for angulated abutments than for axial ones. All marginal bone changes were higher in maxillary implants, but only for marginal bone loss after 12 months were differences statistically significant.

Conclusions: Within the limitations of this study, 3-mm angulated abutments had significantly more marginal bone loss after 12 months and more bone remodeling after 6 months than $3 \mathrm{~mm}$ axial ones. Axial abutment height and angulated abutment side did not significantly influence marginal bone loss nor bone remodeling. Maxillary implants showed significantly more marginal bone loss than mandibular implants after 1 year of functional loading. More clinical studies with better design and longer follow-up are necessary to address this topic.

Keywords: Immediate loading; dental implant; bone loss; abutment; fixed prosthesis; full-arch

Received: 14 May 2021; Accepted: 09 September 2021; Published: 10 December 2021.

doi: 10.21037/fomm-21-64

View this article at: https://dx.doi.org/10.21037/fomm-21-64 


\section{Introduction}

Implant-supported full-arch fixed dental implant prostheses have showed high survival rates between $84.3 \%$ to $100 \%$ according several studies $(1,2)$. This type of prosthetic solution rehabilitates the function and anatomy of edentulous patients and provides high patient satisfaction (3).

According to implant loading timing, different protocols have been described to rehabilitate edentulous patients: immediate loading is the establishment of occlusal function during the first week after placement, early loading occurs between 1 week and 2 months, and conventional loading is performed after 2 months or more (4).

Patient satisfaction for immediate loading was significantly higher than for conventional loading during the osseointegration period (5). The immediate loading protocol achieved a faster resumption of oral function, improving esthetics, decreasing morbidity by avoiding a second surgical procedure, and omitting the need for removable conventional dentures during the osseointegration period $(6,7)$.

The use of tilted dental implants in atrophic upper or lower jaws achieved the reduction of the prosthetic cantilever, a better load distribution, the elimination of the necessity of bone grafts and the improvement of primary stability to implement the immediate loading $(8,9)$. Implant success rate and marginal bone loss of tilted and axial dental implants have not shown statistically significant differences (9). This angulation consequently requires the use of angulated abutments for a more optimal prosthetic emergence. Angulated abutments are more bulky than axial ones because they have to correct the implant angulation at the same time that they provide space for the screws; the consequence is that they leave less space to peri-implant soft tissues. Changes in soft tissue dimensions are known to affect peri-implant marginal bone changes (10). Moreover, contrarily to axial abutments, angulated abutments are not symmetric. However, the possible differences between mesial and distal sites of angulated abutments have not yet been studied.

The use of prosthetic abutment is mandatory to achieve passive fit between implant connection and prosthesis in multi dental implant prosthesis. Abutment height is selected depending on implant crestal position and peri-implant mucosa vertical thickness. Abutment height influences periimplant marginal bone loss. This has been mainly addressed in partially edentulous patients (11): $\geq 2$ abutment height prevented the marginal bone loss compared to $<2 \mathrm{~mm}$ abutment height. There is a lack of information in the current literature analyzing the influence on peri-implant marginal bone loss and marginal bone remodeling of abutment height in immediate loading implant-supported full-arch fixed prosthetic restoration.

The present retrospective study aimed to evaluate the influence of axial abutment height, abutment angulation, angulated abutment side and implant site on peri-implant marginal bone loss and marginal bone remodeling after 1-year follow-up in immediate loading implantsupported full-arch fixed prosthesis. The following article is presented in accordance with the STROBE reporting checklist (available at https://fomm.amegroups.com/article/ view/10.21037/fomm-21-64/rc).

\section{Methods}

\section{Study design}

This retrospective case series study included patients treated with immediate loading implant-supported full-arch fixed dental prostheses with a follow-up of 1 year. All the patients were surgically treated by the same oral surgeon and prosthetically rehabilitated by the same prosthodontist in the Oral Surgery Unit, Department of Stomatology, Faculty of Medicine and Dentistry, University of Valencia. The clinical and radiographic databases of this Oral Surgery Unit were consulted to collect the necessary information.

Every included subject signed an informed consent to participate in the study. The study was conducted in accordance with the Declaration of Helsinki, and the study protocol was approved by the Ethics Committee of the University of Valencia (H1275992266359).

\section{Operational procedure}

A preoperative study was performed: anamnesis, clinical history and preoperative panoramic radiography and cone beam computerized tomography (CBCT). The intermaxillary relationships and prosthetic lines (midline, smile and canine line) were stablished prior to the surgical intervention.

The intervention day, intravenous conscious sedation was performed by means midazolam $0.05 \mathrm{mg} / \mathrm{kg}$ and fentanyl $1 \mathrm{mg} / \mathrm{kg}$. When adequate sedation was achieved, injection of the local anesthetic (4\% articaine with $1 / 200,000$ adrenalin) was performed. If the patient remained too awake, propofol was administered in subanesthetic doses of 0.3 to $0.5 \mathrm{mg} / \mathrm{kg}$. Sedation was maintained by means of $1 \mathrm{mg}$ midazolam, 

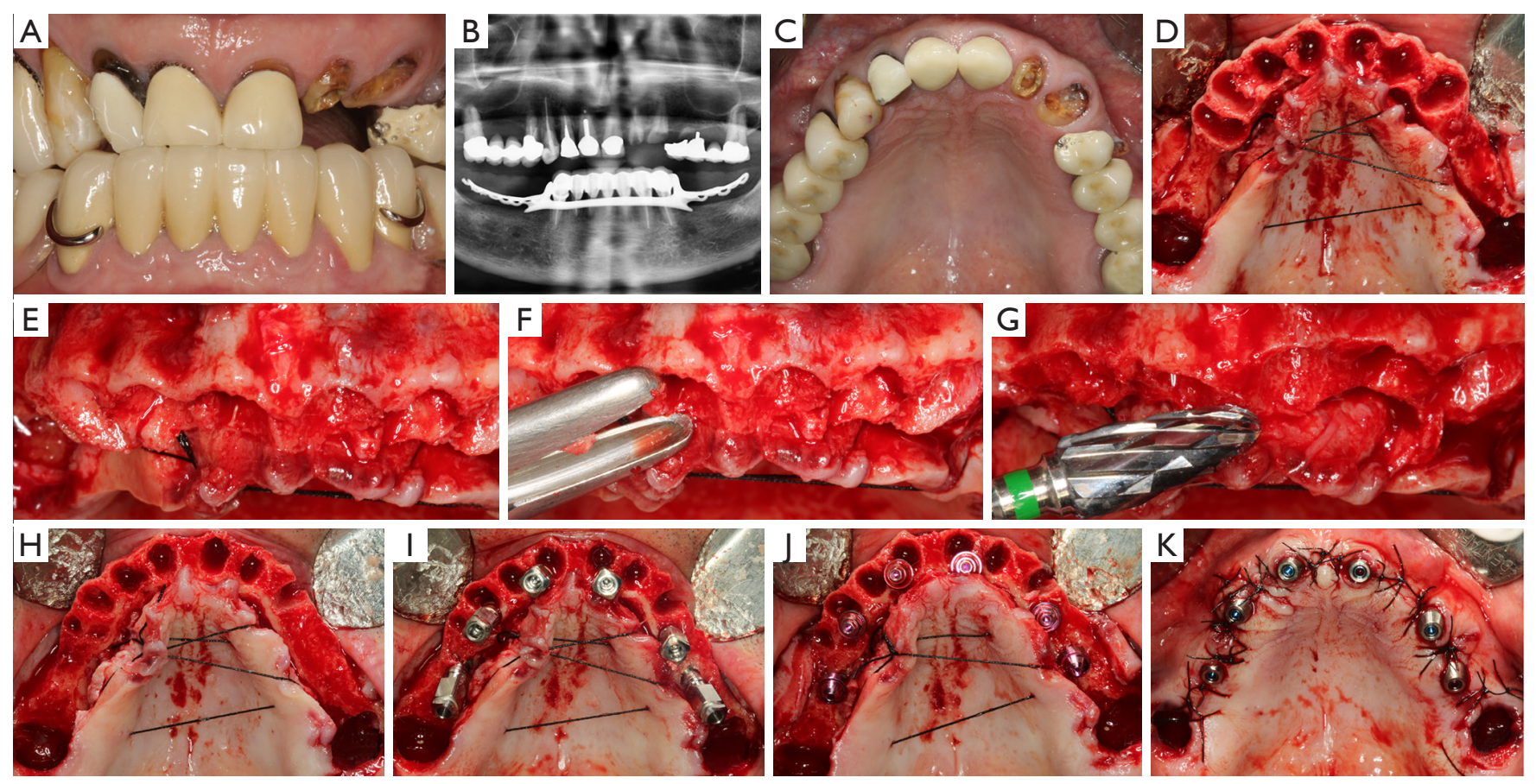

Figure 1 Surgical phase to rehabilitate the upper jaw with an immediate loading fixed full-arch implant-supported prosthesis. (A) Frontal preoperative intraoral image; (B) preoperative panoramic radiography; (C) occlusal preoperative intraoral image; (D) the remaining teeth were extracted and a mucoperiosteal flap was raised; (E) the alveolar process needed a bone regularization; (F) the gouge forceps was used to regularize the alveolar process; $(\mathrm{G})$ a surgical bur were used to regularize the alveolar process too; $(\mathrm{H})$ the alveolar process after the bone regularization; (I) six dental implants IPX ${ }^{\circledR}$ (Galimplant S.L, Sarria, Spain) were placed. The two distal implants were tilted; (J) dental implant abutments were placed in each dental implant; (K) healing plugs were put on the dental implant abutments.

0.5 to $1 \mathrm{mg} / \mathrm{kg}$ fentanyl, and bolus doses of propofol of $20 \mathrm{mg}$ every 30 or 60 minutes depending on the state of the patient and depth of anesthesia. The surgical and sedation procedures were performed with basic continuous and noninvasive monitoring of electrocardiography, heart rate, blood pressure, and arterial oxygen saturation (12).

A supra-crestal incision with a mucoperiosteal flap lift was performed. The implant placement was sub-crestal. Two- or 3-mm high axial and 3- or 4-mm high angulated abutments were selected depending on the implant position and the vertical thickness of the peri-implant mucosa (Figure 1). All the patients were treated with the same type of dental implants (4 mm of diameter, IPX ${ }^{\circledR}$, Galimplant S.L., Sarria, Spain) and original abutments from the same company. The implant design is a bone-level implant with conical connection and switching platform.

The implant positions were registered intraoperatively following the protocol used in Peñarrocha-Oltra et al. (6). A specific and original immediate loading abutment from the same company was placed on the implant abutment. Sterile pieces of rubber dam were used to protect the surgical field. The immediate loading abutments were then splinted to the template with DuraLay resin (Reliance Dental Manufacturing). This information was transferred to the patient's diagnostic cast and used to make a polymethyl methacrylate (PMMA) provisional full-arch screwed prosthesis with no distal cantilevers, which was placed within 24 hours from the implant surgery. The occlusion was adjusted to achieve an even distribution of forces. A metal composite or metal ceramic prosthesis was placed as the definitive prosthesis 6 months later (Figure 2).

\section{Selection criteria}

The patients were included if the immediate loading implant-supported full-arch fixed dental prostheses was the rehabilitation option, if the treatment was followed during 1 year, if the clinical history was complete and if panoramic radiographies were available after immediate loading prosthesis placement (T1), after definitive prosthesis 

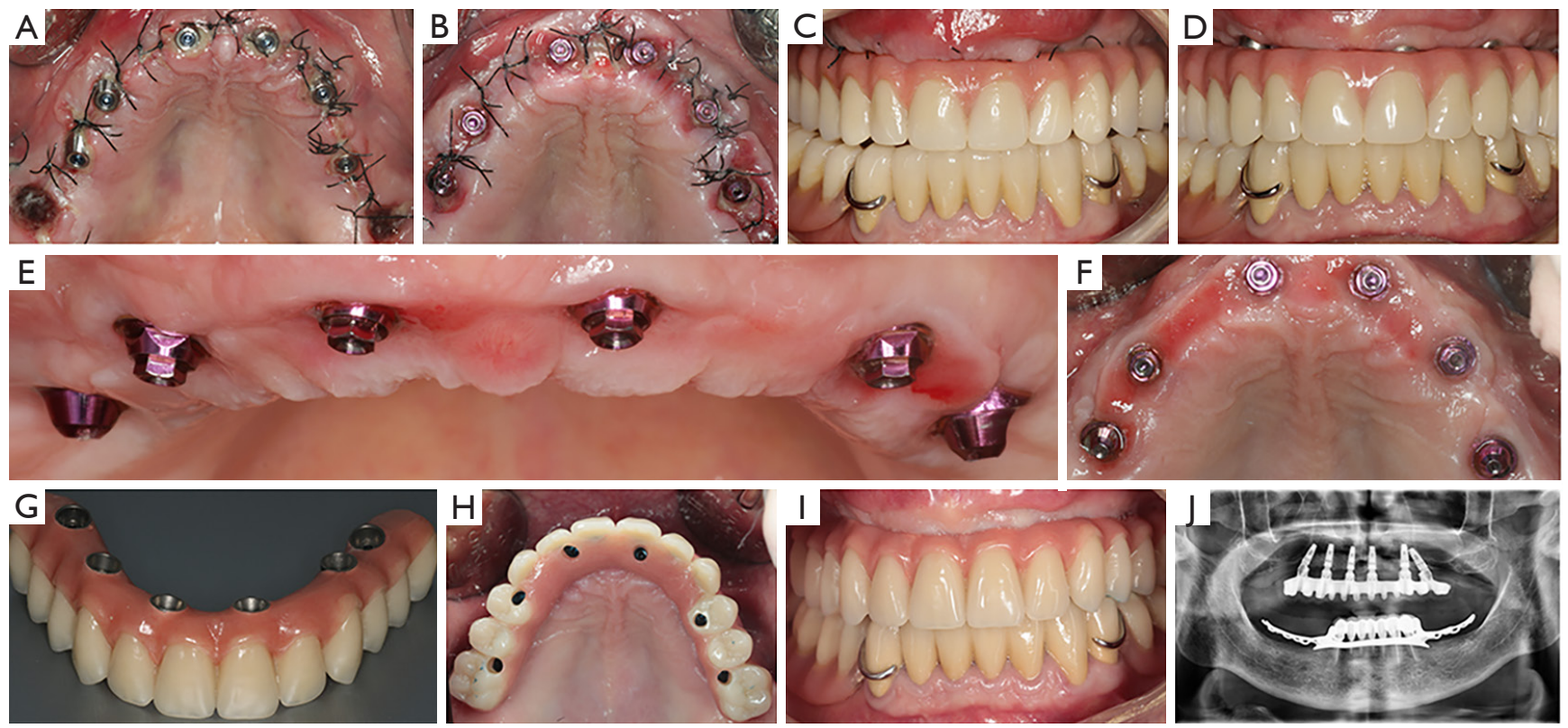

Figure 2 Prosthetic phase to rehabilitate the upper jaw with an immediate loading fixed full-arch implant-supported prosthesis. (A) The mucosal healing after 24 hours with the healing plugs; (B) the mucosal healing after 24 hours around the dental implant abutments; (C) placement of the immediate loading resin hybrid prosthesis after 24 hours; (D) immediate loading hybrid prosthesis after 6 months was fabricated with reinforced metal resin material; (E) frontal vision of the mucosa after 6 months to the intervention; (F) occlusal vision of the mucosa after 6 months to the intervention; $(G)$ hybrid implant-supported full-arch fixed dental prostheses was fabricated with metal composite; $(\mathrm{H})$ occlusal view of the definitive prosthesis; (I) frontal view in occlusion of the definitive rehabilitation; (J) panoramic radiography after the definitive prosthesis placement.

placement at 6 months (T2) and 12 months after implant placement (T3). The patients were excluded if radiographic artifacts impeded the correct measurement of peri-implant marginal bone loss.

\section{Data collection}

The clinical histories and panoramic radiographies were retrieved to extract: sex, age, implant number, implant length, axial abutment height, abutment angulation (Figure 3), angulated abutment side (mesial and distal) and implant site (maxilla or mandible), implant survival, periimplant marginal bone loss and marginal bone remodeling at 6 and 12 months of follow-up. Implant failure was evaluated according to Buser et al. (13): (I) absence of clinically detectable implant mobility; (II) absence of pain or any subjective sensation; (III) absence of recurrent periimplant infection; and (IV) absence of persistent radiotransparency around the implant after 12 months of loading.

\section{Measurement of peri-implant marginal bone loss and marginal bone remodeling}

Panoramic radiographies (Planmeca Promax ${ }^{\circledR}$ 3D Max and 2D S3, Helsinki, Finland) were used to analyze the peri-implant marginal bone level after immediate loading prosthesis placement (T1), after the definitive prosthesis placement at 6 months (T2) and after definitive prosthesis placement at 12 months (T3).

Radiological measurements were performed using CliniView 6.1.3.7 (Instrumentarium, Valencia, Spain) software program. The calibration of each measurement was performed using as reference the $4 \mathrm{~mm}$ of the implant diameter. Two marginal bone levels were indicated for each implant: one in apical direction to calculate marginal bone loss and another in coronal direction to calculate bone remodeling (Figure 4). Peri-implant marginal bone loss was defined as bone-level changes occurring apical to the implant platform and therefore leaving part of the rough surface of the implant without bone cover. To calculate this 

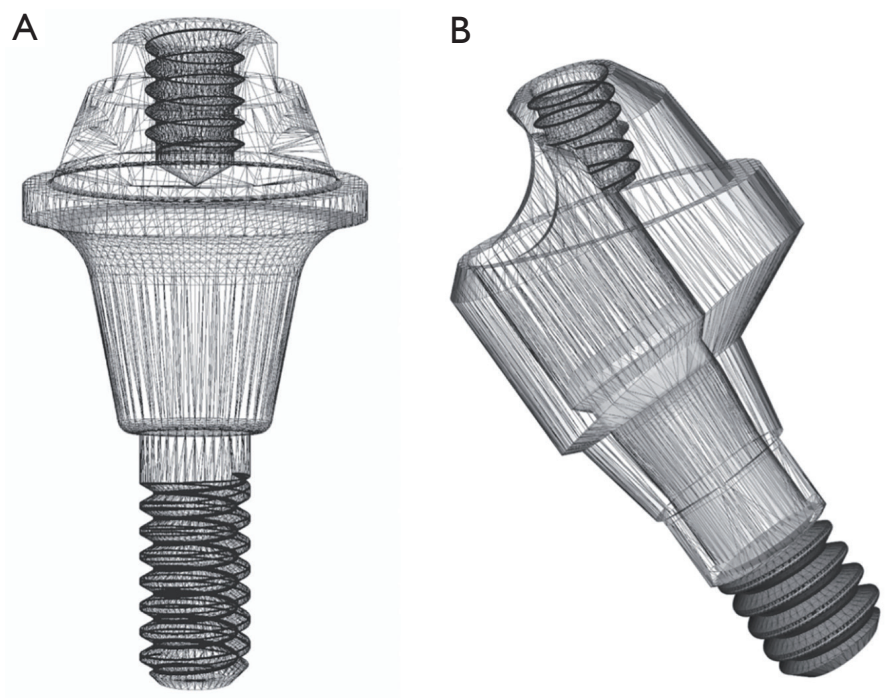

Figure 3 Schematic image of the different morphology between the axial and angulated abutment. (A) Axial abutment; (B) angulated abutment.

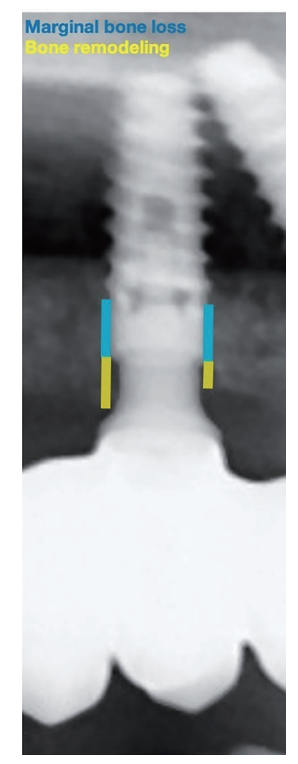

Figure 4 Schematic image show the two marginal bone level: the differences after 6 and 12 months in apical direction (blue line) were used to calculate marginal bone loss and the differences after 6 and 12 months in coronal direction (yellow line) were used to evaluated bone remodeling.

variable, bone levels at each time point were determined from the implant platform to the first radiographic bone-toimplant contact after 6 months (difference between T1 and $\mathrm{T} 2$ ) and 12 months (difference between $\mathrm{T} 1$ and T2). Bone remodeling was defined as bone-level changes occurring coronal to the implant platform and therefore causing no exposure of the rough implant surface. To calculate this variable, bone levels at each time point were determined from implant platform to the marginal bone crest after 6 months (difference between T1 and T2) and 12 months (difference between $\mathrm{T} 1$ and $\mathrm{T} 3$ ). The mean value from the medial and distal measurements was calculated for each implant. For angulated abutments, mesial and distal marginal bone level changes were calculated separately too. All radiographic measurements were recorded by the same experienced measurer.

\section{Statistical analysis}

The mean marginal bone loss and bone remodeling were calculated after 6 and 12 months of functional loading. Covariates on marginal bone loss and bone remodeling was sought for abutment height within the axial abutments group ( 2 s. $3 \mathrm{~mm}$ ), implant abutment angulation (axial $v s$. angulated), implant abutment angulation within $3 \mathrm{~mm}$ abutment height, the angulated abutment side (mesial vs. distal) within the angulated $3 \mathrm{~mm}$ abutments group and the implant site (maxilla $v s$. mandible). The mean values and standard deviations were calculated. A Shapiro-Wilk test was used for normality test. The $t$-test is used to detect differences in parametric variables if the normality hypothesis is accepted. Otherwise, the nonparametric 
Table 1 Implant length distribution

\begin{tabular}{lccccccc}
\hline \multirow{2}{*}{ Arch } & \multicolumn{5}{c}{ Implant length $(\mathrm{mm})$} & \multicolumn{1}{c}{ Total } \\
\cline { 2 - 6 } & 8.0 & 10.0 & 12.0 & 14.0 & 16.0 & 18.0 \\
\hline Mandible & 2 & 4 & 8 & 8 & 7 & 3 & 32 \\
Maxilla & 0 & 2 & 26 & 13 & 6 & 8 & 13 \\
Total & 2 & 6 & 34 & 21 & 13 & 87 \\
\hline
\end{tabular}

Table 2 Mean differences on marginal bone loss and bone remodeling

\begin{tabular}{|c|c|c|c|c|c|c|c|c|c|}
\hline Follow-up & $\mathrm{N}$ & \multicolumn{4}{|c|}{ Marginal bone loss } & \multicolumn{4}{|c|}{ Bone remodeling } \\
\hline 6 months (T1-T2) & 87 & -0.24 & 0.89 & 0.09 & $0.01^{*}$ & -0.56 & 0.58 & 0.06 & $0.00^{*}$ \\
\hline 12 months (T1-T3) & 87 & -0.51 & 1.04 & 0.11 & $0.00^{\star}$ & -0.82 & 0.84 & 0.09 & $0.00^{\star}$ \\
\hline
\end{tabular}

*, statistical significance Wilcoxon signed-rank test. N, implant number; SD, standard deviation.

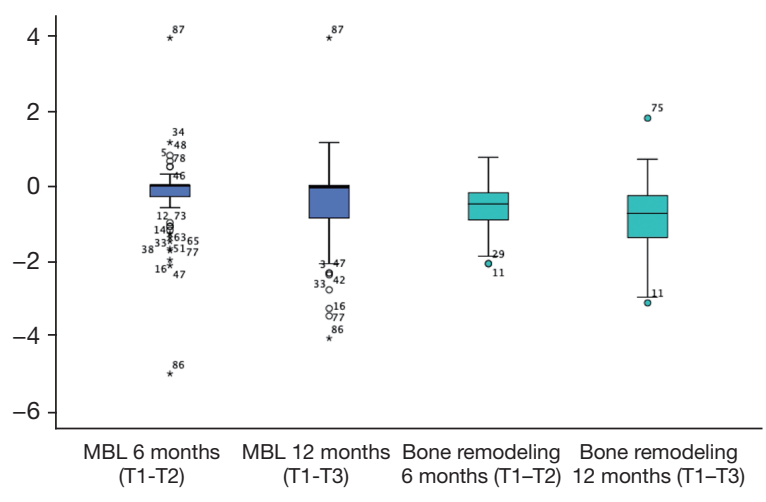

Figure 5 Mean marginal bone loss and bone remodeling after 6 and 12 months of functional loading. MBL, marginal bone loss.

test (Friedman and Wilcoxon tests) for related samples or Mann-Whitney $U$ test for independent samples were applied for statistical analysis, respectively. The primary variables of the study are bone loss at 6 and 12 months. Using the Shapiro-Wilk test, it is concluded that there is not enough statistical evidence to reject normality $(\mathrm{P}=0.623$ and $\mathrm{P}=0.301$, respectively), so a parametric analysis approach will be developed. Simple general linear models will be applied to assess whether the mean marginal bone loss at a certain time-point is similar at different levels of a factor (gender, age, implant position and abutment angulation and abutment height). Subsequently, the factors detected as influential $(\mathrm{P}<0.1)$ will be incorporated into a multiple regression model and thus obtain adjusted beta coefficients. These models are estimated under the generalized estimation equations (GEE) approach to control the dependence of the observations due to the multiplicity of implants per patient. The $\chi^{2}$ statistic of Wald will be used to evaluate main effects and interactions. The level of significance used in the analyses has been $5 \%(\alpha=0.05)$. The level of statistical significance was set at $\mathrm{P}<0.05$. The IBM SPSS 25.0 software package for Mac is used for analyses.

\section{Results}

Seventeen patients ( 5 men and 12 women) fulfilled the selection criteria. Three patients were excluded because marginal bone changes could not be measured in at least one of the implants due to radiographic artifacts. The mean age was 65.71 (35-79 years). No implant failed during the observation period. Table 1 expose the implant site and implant length according to maxillary or mandibular implant placement.

Mean marginal bone loss and bone remodeling after 12 months of functional loading were $-0.51 \pm 1.04$ and $-0.81 \pm 0.84 \mathrm{~mm}$, respectively (Table 2 ). The mean marginal bone loss and bone remodeling at 6 and 12 months are visually depicted in Figure 5.

Within axial abutments, $3 \mathrm{~mm}$ height abutments showed lesser marginal bone loss and bone remodeling values than $2 \mathrm{~mm}$ abutments, but differences did not reach statistical significance (Table 3).

When the whole sample of implants was considered, angulated abutments showed more marginal bone loss and bone remodeling than axial abutments after 6 and 
Table 3 Marginal bone loss and bone remodeling differences between different axial prosthetic abutments heights

\begin{tabular}{|c|c|c|c|c|c|c|c|c|c|}
\hline Differences & $\mathrm{N}$ & \multicolumn{4}{|c|}{ Marginal bone loss } & \multicolumn{4}{|c|}{ Bone remodeling } \\
\hline \multicolumn{10}{|l|}{ 2-mm height } \\
\hline 6 months (T1-T2) & 21 & -0.11 & 0.38 & 0.08 & 0.117 & -0.57 & 0.60 & 0.13 & $0.002^{*}$ \\
\hline 12 months (T1-T3) & 21 & -0.27 & 0.54 & 0.12 & $0.035^{\star}$ & -0.8 & 0.84 & 0.18 & 0.096 \\
\hline 6 months (T1-T2) & 21 & -0.03 & 0.16 & 0.03 & 0.360 & -0.78 & 0.50 & 0.10 & $0.000^{*}$ \\
\hline 12 months (T1-T3) & 21 & -0.20 & 0.37 & 0.08 & 0.030 & -1.05 & 0.67 & 0.14 & $0.000^{*}$ \\
\hline 2 vs. $3 \mathrm{~mm}$ at 6 months (T1-T2) & 42 & -0.08 & 0.44 & 0.09 & 0.397 & 0.21 & 0.33 & 0.05 & 0.217 \\
\hline 2 vs. $3 \mathrm{~mm}$ at 12 months (T1-T3) & 42 & -0.075 & 0.75 & 0.16 & 0.620 & 0.25 & 0.46 & 0.04 & 0.286 \\
\hline
\end{tabular}

*, statistical significance Wilcoxon signed-rank test. N, implant number; SD, standard deviation; SE, standard error.

Table 4 Marginal bone loss and bone remodeling according to the abutment angulation

\begin{tabular}{|c|c|c|c|c|c|c|c|c|c|}
\hline Differences & $\mathrm{N}$ & \multicolumn{4}{|c|}{ Marginal bone loss } & \multicolumn{4}{|c|}{ Bone remodeling } \\
\hline \multicolumn{10}{|l|}{ Axial abutment } \\
\hline 6 months (T1-T2) & 42 & -0.26 & 0.60 & 0.09 & $0.006^{*}$ & -0.67 & 0.57 & 0.08 & $0.000^{*}$ \\
\hline 12 months (T1-T3) & 42 & -0.58 & 0.97 & 0.14 & $0.000^{*}$ & -0.91 & 0.79 & 0.12 & $0.000^{*}$ \\
\hline 6 months (T1-T2) & 45 & -0.23 & 1.02 & 0.15 & 0.149 & -0.45 & 0.58 & 0.08 & $0.000^{*}$ \\
\hline 12 months (T1-T3) & 45 & -0.46 & 1.06 & 0.16 & $0.007^{*}$ & -0.74 & 0.88 & 0.13 & $0.000^{*}$ \\
\hline Axial vs. tilted at 6 months (T1-T2) & 87 & -0.02 & 1.01 & 0.15 & 0.869 & -0.22 & 0.24 & 0.13 & 0.074 \\
\hline Axial vs. tilted at 12 months (T1-T3) & 87 & -0.12 & 1.24 & 0.19 & 0.520 & -0.17 & 0.35 & 0.18 & 0.342 \\
\hline
\end{tabular}

*, statistical significance Wilcoxon signed-rank test. N, implant number; SD, standard deviation; SE, standard error.

12 months, without statistically significant differences (Table 4). These findings are visually depicted in Figure $6 \mathrm{~A}, 6 \mathrm{~B}$. When only $3-\mathrm{mm}$ high axial and angulated abutments were included in the analysis, statistically significant differences were found after 12 months in marginal bone loss $(\mathrm{P}=0.0001)$ and after 6 months in bone remodeling $(\mathrm{P}=0.034)$ (Table 5). For angulated abutments marginal bone loss and bone remodeling were higher in mesial than in distal sides, but differences were not statistically significant (Table 6).

Mandibular implants showed both less marginal bone loss and bone remodeling during follow-up than maxillary implants. The mean difference in marginal bone loss between mandible and maxilla was $0.46 \pm 0.36$ after 12-month follow-up. This difference was statistically significant $(\mathrm{P}=0.001)$. Bone remodeling showed statistically significant changes after 6 and 12 months of functional load $(\mathrm{P} \leq 0.05)$ (Table 7). Differences are visually depicted in Figure 6C,6D.

According to the simple and multiple regression analysis, the only factor that influenced significantly on marginal bone loss at 6 months was the gender $(\mathrm{P}=0.008)$ (Table 8). Women had less bone loss than men. At 12 months (Table 9), the only factor that had a significant influence was age $(\mathrm{P}=0.014)$. The younger patients showed greater marginal bone loss. The implant position, the abutment inclination and the abutment height did not significantly influence bone loss either at 6 or 12 months. The multiple interaction 

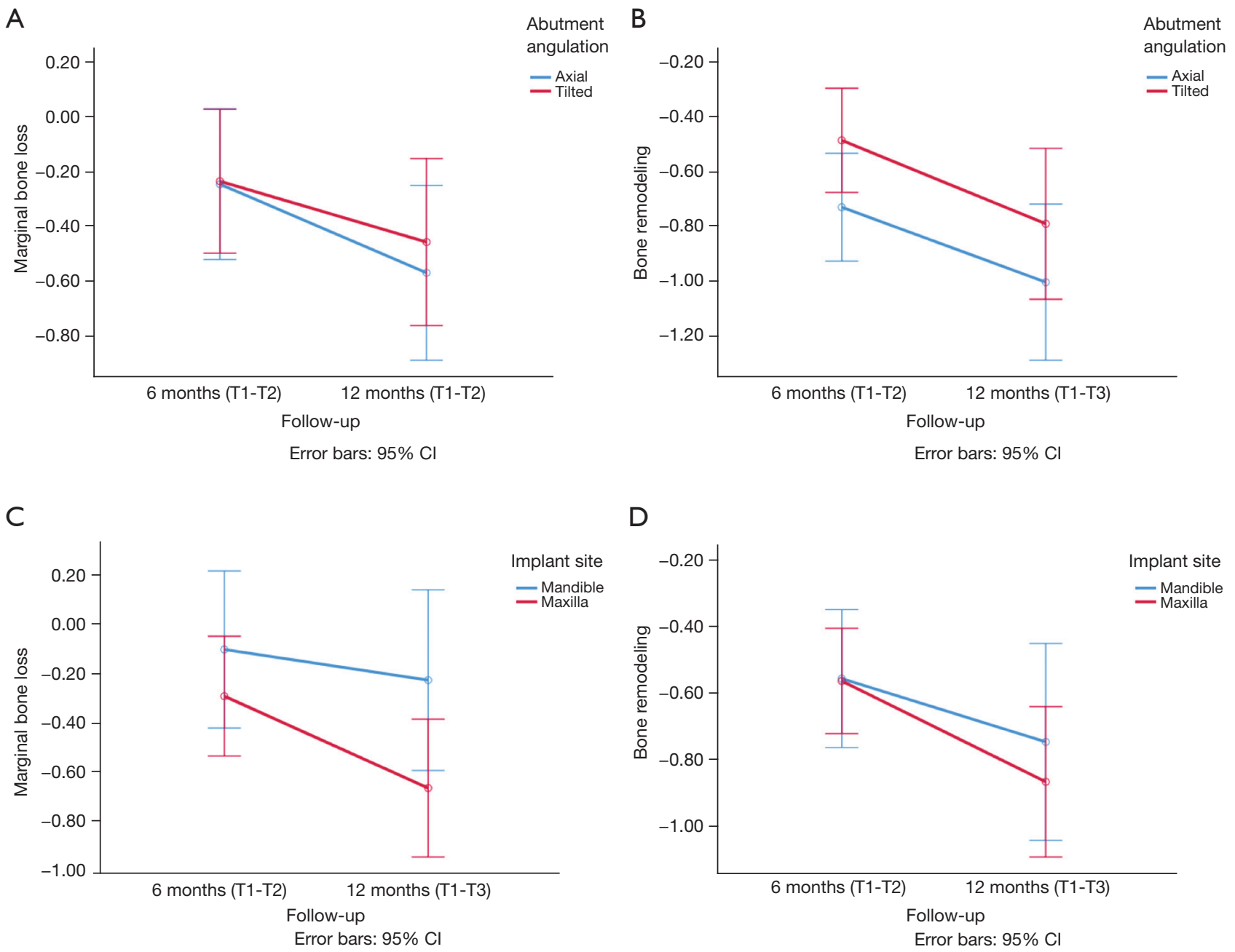

Figure 6 Marginal bone loss and bone remodeling according to the implant inclination (A,B) and implant site (C,D). The maxillary implants presented statistically significant differences in bone remodeling and bone loss compared to mandibular implants. There were not statistically significant differences for the different abutment angulation in bone remodeling and bone loss including different abutment heights.

models do not show statistically significant interactions among factors.

\section{Discussion}

Analyzing the influence of axial abutment height, abutment angulation, angulated abutment side and implant site on peri-implant marginal bone loss and marginal bone remodeling after 1 year of follow-up in immediate loading implant-supported full-arch fixed prosthesis was the aim of this retrospective study.

Immediate loading has been analyzed by several studies with satisfactory outcomes $(2,3,14)$. Peñarrocha-Oltra et al. (6) conducted a prospective controlled non-randomized study in 36 total edentulous patients (18 per group) with a 12-month follow-up. The fixed full-arch rehabilitations were supported by conventional loading (control group) and immediate loading (test group). One hundred and eighty-three dental implants were placed and the implant success rates were $99.0 \%$ in conventional loading group and $97.6 \%$ in immediate loading group without statistically significant differences. All immediately loaded prostheses were successful. Mean bone loss was $0.71 \mathrm{~mm}$ (standard deviation $0.25 \mathrm{~mm}$ ) in the immediate loading group and 
Table 5 Marginal bone loss and bone remodeling differences between axial and angulated abutments with the same height (3 mm)

\begin{tabular}{|c|c|c|c|c|c|c|c|c|c|}
\hline Differences & $\mathrm{N}$ & \multicolumn{4}{|c|}{ Marginal bone loss } & \multicolumn{4}{|c|}{ Bone remodeling } \\
\hline \multicolumn{10}{|l|}{ Angulated $3 \mathrm{~mm}$} \\
\hline 6 months (T1-T2) & 45 & -0.23 & 1.02 & 0.15 & $0.149^{*}$ & -0.45 & 0.58 & 0.08 & $0.000^{*}$ \\
\hline 12 months (T1-T3) & 45 & -0.46 & 1.06 & 0.16 & $0.007^{*}$ & -0.74 & 0.88 & 0.13 & $0.000^{*}$ \\
\hline \multicolumn{10}{|l|}{ Axial $3 \mathrm{~mm}$} \\
\hline 6 months (T1-T2) & 21 & -0.03 & 0.16 & 0.03 & 0.360 & -0.78 & 0.50 & 0.10 & $0.000^{*}$ \\
\hline 12 months (T1-T3) & 21 & -0.24 & 0.37 & 0.08 & $0.027^{*}$ & -1.05 & 0.67 & 0.14 & $0.000^{*}$ \\
\hline Angulated vs. axial at 6 months (T1-T2) & 66 & -0.20 & 0.31 & 0.03 & 0.199 & 0.330 & 0.68 & 0.08 & $0.034^{\star \star}$ \\
\hline Angulated vs. axial at 12 months (T1-T3) & 66 & -0.70 & 0.35 & 0.04 & $0.000^{\star \star}$ & 0.310 & 1.07 & 0.13 & 0.372 \\
\hline
\end{tabular}

*, statistical significance Wilcoxon signed-rank test; ${ }^{* *}$, statistical significance Mann-Whitney U test. N, implant number; SD, standard deviation; SE, standard error.

Table 6 Marginal bone loss and bone remodeling differences at mesial and distal sides in angulated abutment of $3 \mathrm{~mm}$ of height

\begin{tabular}{|c|c|c|c|c|c|c|c|c|}
\hline Differences & $\mathrm{N}$ & Mean & SD & SE & \multicolumn{4}{|c|}{ Mesial vs. distal } \\
\hline \multicolumn{9}{|c|}{ Marginal bone loss } \\
\hline \multicolumn{9}{|c|}{6 months (T1-T2) } \\
\hline Mesial & 45 & -0.19 & 0.42 & 0.06 & -0.12 & 0.61 & 0.08 & 0.11 \\
\hline \multicolumn{9}{|c|}{12 months (T1-T3) } \\
\hline Mesial & 45 & -0.35 & 0.59 & 0.09 & -0.15 & 0.70 & 0.10 & 0.13 \\
\hline Distal & 45 & -0.20 & 0.54 & 0.08 & & & & \\
\hline \multicolumn{9}{|c|}{ Bone remodeling } \\
\hline Distal & 45 & -0.11 & 2.40 & 0.36 & & & & \\
\hline \multicolumn{9}{|c|}{12 months (T1-T3) } \\
\hline Mesial & 45 & -0.76 & 1.68 & 0.25 & -0.42 & 1.46 & 0.22 & 0.13 \\
\hline Distal & 45 & -0.34 & 2.39 & 0.36 & & & & \\
\hline
\end{tabular}

$\mathrm{N}$, implant number; SD, standard deviation; SE, standard error.

$0.60 \mathrm{~mm}$ (standard deviation $0.28 \mathrm{~mm}$ ) in the conventional loading group without statistically significant differences. Tealdo et al. (15) conducted a prospective randomized study with 36-month follow-up on 49 patients with 34 immediate loaded dental implants and 15 convectional loaded dental implants. The results showed success rate of $93.3 \%$ for immediate loading (10 failed implant) and of $95.5 \%$ for conventional loading (4 failed implant), without statistically significant differences. No implant failed in the present study. This might be explained by the reduced sample and follow-up.

According to Linkevicius et al. (16), subcrestal implant 
Table 7 Marginal bone loss and bone remodeling differences according to the implant location

\begin{tabular}{|c|c|c|c|c|c|c|c|c|c|}
\hline Differences & $\mathrm{N}$ & \multicolumn{4}{|c|}{ Marginal bone loss } & \multicolumn{4}{|c|}{ Bone remodeling } \\
\hline \multicolumn{10}{|l|}{ Mandible } \\
\hline 6 months (T1-T2) & 32 & -0.09 & 0.24 & 0.04 & $0.03^{*}$ & -0.56 & 0.67 & 0.11 & $0.00^{\star}$ \\
\hline 12 months (T1-T3) & 32 & -0.22 & 0.46 & 0.08 & $0.01^{*}$ & -0.75 & 0.82 & 0.14 & $0.00^{*}$ \\
\hline 6 months (T1-T2) & 55 & -0.32 & 1.10 & 0.14 & $0.03^{*}$ & -0.66 & 0.56 & 0.07 & $0.00^{\star}$ \\
\hline 12 months (T1-T3) & 55 & -0.68 & 1.23 & 0.16 & $0.00^{*}$ & -0.92 & 0.95 & 0.12 & $0.00^{*}$ \\
\hline Mandible vs. maxilla at 6 months (T1-T2) & 87 & 0.23 & 0.30 & 0.14 & 0.13 & 0.10 & 0.93 & 0.16 & 0.53 \\
\hline Mandible vs. maxilla at 12 months (T1-T3) & 87 & 0.46 & 0.36 & 0.19 & $0.01^{\star *}$ & 0.17 & 1.28 & 0.22 & 0.45 \\
\hline
\end{tabular}

*, statistical significance Wilcoxon signed-rank test; ${ }^{* *}$, statistical significance t-test. $\mathrm{N}$, implant number; SD, standard deviation; SE, standard error.

Table 8 The marginal bone loss at 6 months according to independent factors: results of simple and multiple linear regression models (adjusted) with generalized estimation equations (GEE). B coefficients, 95\% confidence intervals (CIs) and P value of the Wald $\chi^{2}$ test

\begin{tabular}{|c|c|c|c|c|c|c|}
\hline Variables & \multicolumn{3}{|c|}{ Simple model } & \multicolumn{3}{|c|}{ Adjusted model } \\
\hline \multicolumn{7}{|l|}{ Gender } \\
\hline Male & 0 & & & 0 & & \\
\hline Female & 0.41 & 0.11 to 0.71 & $0.008^{\star \star}$ & 0.37 & 0.07 to 0.66 & $0.015^{\star}$ \\
\hline \multicolumn{7}{|c|}{ Implant position } \\
\hline Maxilla & 0 & & & & & \\
\hline Mandible & -0.02 & -0.39 to 0.35 & 0.905 & - & - & - \\
\hline \multicolumn{7}{|c|}{ Abutment inclination } \\
\hline \multicolumn{7}{|c|}{ Abutment height } \\
\hline $2 \mathrm{~mm}$ & 0 & & & & & \\
\hline $3 \mathrm{~mm}$ & -0.06 & -0.33 to 0.21 & 0.652 & - & - & - \\
\hline
\end{tabular}

${ }^{*}, \mathrm{P}<0.05 ;{ }^{* \star}, \mathrm{P}<0.01$.

placement is a proposed method to avoid marginal bone loss in thin mucosa areas. This type of placement has bone above the implant platform that could be important to maintain healthy the peri-implant tissue. Marginal bone loss and marginal bone remodeling are well differentiated variables in recent studies (16).

Galindo-Moreno et al. (11) demonstrated in a retrospective study with 308 dental implants that abutment height could influence the marginal bone loss. Marginal bone loss was significantly superior for $<2$ than $\geq 2 \mathrm{~mm}$ prosthetic abutment heights. These results could be related with the soft tissue thickness. Linkevicius et al. (17) demonstrated that $2 \mathrm{~mm}$ of soft tissue thickness was the minimum to avoid the peri-implant marginal bone loss. 
Table 9 The marginal bone loss at 12 months according to independent factors: results of simple and multiple linear regression models (adjusted) with generalized estimation equations (GEE). B coefficients, $95 \%$ confidence intervals (CIs) and P value of the Wald $\chi^{2}$ test

\begin{tabular}{|c|c|c|c|c|c|c|}
\hline Variables & \multicolumn{3}{|c|}{ Simple model } & \multicolumn{3}{|c|}{ Adjusted model } \\
\hline \multicolumn{7}{|l|}{ Gender } \\
\hline Male & 0 & & & & & \\
\hline Female & 0.24 & -0.390 to 0.86 & 0.460 & - & - & - \\
\hline \multicolumn{7}{|c|}{ Implant position } \\
\hline Maxilla & 0 & & & & & \\
\hline Mandible & 0.11 & -0.35 to 0.57 & 0.635 & - & - & - \\
\hline \multicolumn{7}{|c|}{ Abutment inclination } \\
\hline \multicolumn{7}{|c|}{ Abutment height } \\
\hline $2 \mathrm{~mm}$ & 0 & & & & & \\
\hline $3 \mathrm{~mm}$ & 0.01 & -0.43 to 0.46 & 0.949 & - & - & - \\
\hline
\end{tabular}

*, $P<0.05$.

However, if this thickness is greater than $2 \mathrm{~mm}$ and the height of the abutment could be chosen, low abutment heights $(<2 \mathrm{~mm})$ would still lose a greater proportion of peri-implant bone due to the compression of the periimplant mucosa (18). The present study was retrospective and patients were treated after knowing the outcomes of these investigations. For this reason, no abutments $<2 \mathrm{~mm}$ were used. No statistically significant differences between 2- and 3-mm abutment heights were observed, so $2 \mathrm{~mm}$ seems to be sufficient to ensure favorable peri-implant bone behavior.

Regarding dental implant angulation, Ata-Ali et al. (19) analyzed in a meta-analysis the marginal bone loss and implant success rate for oral rehabilitations with tilted implants. They separately meta-analyzed seven retrospective studies and six prospective studies. The success rate was retrospectively calculated for 166 tilted implants and 241 axial implants and prospectively for 379 tilted and 425 axial implants. The marginal bone loss was prospectively studied for 230 tilted and 270 axial implants. No statistically significant differences in success rate and in marginal bone loss were detected for any study design. Hopp et al. (20) retrospectively compared the marginal bone loss and implant success rate between axial and tilted implants in maxillary All-on-4 treatment concept with 5 years of followup. The study included 2,379 implants (1,201 axial, 1,178 tilted) and there were no statistically significant differences between axial and tilted implants regarding marginal bone loss ( $1.14 \pm 0.71$ and $1.19 \pm 0.82 \mathrm{~mm}$, respectively) nor implant success rate $(95.7 \%$ and $96.1 \%$, respectively). Angulated abutments are always currently used in combination with tilted implants.

When the whole sample of implants was considered, angulated abutments showed more marginal bone loss and bone remodeling than axial abutments after 6 and 12 months, without statistically significant differences (Table 4). These findings are visually depicted in Figure $6 A, 6 B$. When only $3-\mathrm{mm}$ high axial and angulated abutments were included in the analysis, statistically significant differences were found after 12 months in marginal bone loss $(\mathrm{P}=0.0001)$ and after 6 months in bone remodeling $(\mathrm{P}=0.034)$ (Table 5). For angulated abutments marginal bone loss and bone remodeling were higher in mesial than in distal sides, but differences were not statistically significant (Table 6).

On average, the mean marginal bone loss and bone remodeling tend to be higher for the angulated abutments, despite no statistical significance. In an attempt to better 
compare the influence of abutment angulation, reducing confusion, the present study attempted to compare bone level changes between axial and angulated abutments with exactly the same height: $3 \mathrm{~mm}$. Higher marginal bone loss after 12 months were observed to angulated abutments than axial abutments. These findings on marginal bone loss align with the results provided in a meta-analysis of Omori et al. (21), who concluded that implants supporting angulated abutments yielded significantly more marginal bone loss than those supporting straight abutments.

According to our knowledge, no study has previously compared between mesial and distal marginal bone level changes in angulated abutments. The detected differences in favor of the distal part (although non-significant) may be explained because in the mesial part the abutment design compresses the mesial soft tissues, producing higher marginal bone loss and marginal bone remodeling than in distal part. Katafuchi et al. (22) evaluated the restoration emergence angle and its relationship with peri-implantitis. For bone level implants, the restoration angles superior than $30^{\circ}$ had more prevalence of peri-implantitis than angles equal or inferior than $30^{\circ}$ with statistically significant differences. They hypothesized that convex restoration emergence profiles compress peri-implant soft tissue and cause more marginal bone loss.

The different densities of the maxilla and mandibular bones is known to affect marginal bone loss (23). Like in other studies (24), marginal bone loss was significantly higher in the maxilla than in the mandible in the present study.

The main limitation of this study is its design: it is a retrospective case series (low scientific level). Moreover, the follow-up is short and the sample size was small. Therefore, drawing any conclusion from the outcomes of this study should be done with great caution. Prospective-controlled studies with sample size calculations, and longer follow-up times are necessary to improve the scientific evidence on the influence of abutment characteristics on marginal bone level changes in immediate loading implant-supported fullarch fixed dental prostheses.

\section{Conclusions}

Within the limitations of this study, axial abutment height and angulated abutment side showed no influence on marginal bone loss nor bone remodeling. Comparing axial and angulated abutments of the same height $(3 \mathrm{~mm})$, angulated abutments showed significantly more marginal bone loss after 12 months and more bone remodeling after 6 months than 3-mm axial ones. Maxillary implants showed significantly more marginal bone loss than mandibular implants after 1 year of functional loading. More clinical studies with better design and longer follow-up are necessary to better understand the effect of abutment characteristics on bone level changes around implants rehabilitated with immediate loading fixed full-arch prostheses.

\section{Acknowledgments}

Funding: None.

\section{Footnote}

Provenance and Peer Review: This article was commissioned by the Guest Editor (Mario Pérez-Sayáns) for the series "Marginal Bone Loss in Dental Implants: Factors Affecting and How to Prevent It" published in Frontiers of Oral and Maxillofacial Medicine. The article has undergone external peer review.

Reporting Checklist: The authors have completed the STROBE reporting checklist. Available at https://fomm. amegroups.com/article/view/10.21037/fomm-21-64/rc

Data Sharing Statement: Available at https://fomm. amegroups.com/article/view/10.21037/fomm-21-64/dss

Peer Review File: Available at https://fomm.amegroups.com/ article/view/10.21037/fomm-21-64/prf

Conflicts of Interest: All authors have completed the ICMJE uniform disclosure form (available at https://fomm. amegroups.com/article/view/10.21037/fomm-21-64/coif). The series "Marginal Bone Loss in Dental Implants: Factors Affecting and How to Prevent It" was commissioned by the editorial office without any funding or sponsorship. The authors have no other conflicts of interests to declare.

Ethical Statement: The authors are accountable for all aspects of the work in ensuring that questions related to the accuracy or integrity of any part of the work are appropriately investigated and resolved. Every included subject signed an informed consent to participate in the study. The study was conducted in accordance with the Declaration of Helsinki, and the study protocol was 
approved by the Ethics Committee of the University of Valencia (H1275992266359).

Open Access Statement: This is an Open Access article distributed in accordance with the Creative Commons Attribution-NonCommercial-NoDerivs 4.0 International License (CC BY-NC-ND 4.0), which permits the noncommercial replication and distribution of the article with the strict proviso that no changes or edits are made and the original work is properly cited (including links to both the formal publication through the relevant DOI and the license). See: https://creativecommons.org/licenses/by-nc-nd/4.0/.

\section{References}

1. Abou-Ayash S, Strasding M, Rücker G, et al. Impact of prosthetic material on mid- and long-term outcome of dental implants supporting single crowns and fixed partial dentures: A systematic review and meta-analysis. Eur J Oral Implantol 2017;10 Suppl 1:47-65.

2. Bagegni A, Abou-Ayash S, Rücker G, et al. The influence of prosthetic material on implant and prosthetic survival of implant-supported fixed complete dentures: a systematic review and meta-analysis. J Prosthodont Res 2019;63:251-65.

3. Preciado A, Del Río J, Lynch CD, et al. A new, short, specific questionnaire (QoLIP-10) for evaluating the oral health-related quality of life of implant-retained overdenture and hybrid prosthesis wearers. J Dent 2013;41:753-63.

4. Esposito M, Grusovin MG, Willings M, et al. Interventions for replacing missing teeth: different times for loading dental implants. Cochrane Database Syst Rev 2007;(2):CD003878.

5. Peñarrocha-Oltra D, Peñarrocha-Diago M, Canullo L, et al. Patient-reported outcomes of immediate versus conventional loading with fixed full-arch prostheses in the maxilla: a nonrandomized controlled prospective study. Int J Oral Maxillofac Implants 2014;29:690-8.

6. Peñarrocha-Oltra D, Covani U, Peñarrocha $M$, et al. Immediate versus conventional loading with fixed fullarch prostheses in mandibles with failing dentition: a prospective controlled study. Int J Oral Maxillofac Implants 2015;30:427-34.

7. Scala R, Cucchi A, Ghensi P, et al. Clinical evaluation of satisfaction in patients rehabilitated with an immediately loaded implant-supported prosthesis: a controlled prospective study. Int J Oral Maxillofac Implants 2012;27:911-9.
8. Maló P, Rangert B, Nobre M. "All-on-Four" immediatefunction concept with Brånemark System implants for completely edentulous mandibles: a retrospective clinical study. Clin Implant Dent Relat Res 2003;5 Suppl 1:2-9.

9. Agliardi EL, Francetti L, Romeo D, et al. Immediate rehabilitation of the edentulous maxilla: preliminary results of a single-cohort prospective study. Int J Oral Maxillofac Implants 2009;24:887-95.

10. Díaz-Sánchez M, Soto-Peñaloza D, Peñarrocha-Oltra D, et al. Influence of supracrestal tissue attachment thickness on radiographic bone level around dental implants: A systematic review and meta-analysis. J Periodontal Res 2019;54:573-88.

11. Galindo-Moreno P, León-Cano A, Ortega-Oller I, et al. Prosthetic Abutment Height is a Key Factor in Periimplant Marginal Bone Loss. J Dent Res 2014;93:80S-5S.

12. Bovaira M, Herrero Babiloni A, Jovaní M, et al. Preoperative Anxiety and Its Influence on Patient and Surgeon Satisfaction in Patients Receiving Dental Implant Surgeries Performed Under Intravenous Conscious Sedation. Int J Oral Maxillofac Implants 2017;32:912-8.

13. Buser D, Weber HP, Lang NP. Tissue integration of nonsubmerged implants. 1-year results of a prospective study with 100 ITI hollow-cylinder and hollow-screw implants. Clin Oral Implants Res 1990;1:33-40.

14. Maló P, Rangert B, Nobre M. All-on-4 immediatefunction concept with Brånemark System implants for completely edentulous maxillae: a 1-year retrospective clinical study. Clin Implant Dent Relat Res 2005;7 Suppl 1:S88-94.

15. Tealdo T, Bevilacqua M, Menini M, et al. Immediate versus delayed loading of dental implants in edentulous maxillae: a 36-month prospective study. Int J Prosthodont 2011;24:294-302.

16. Linkevicius T, Puisys A, Linkevicius R, et al. The influence of submerged healing abutment or subcrestal implant placement on soft tissue thickness and crestal bone stability. A 2-year randomized clinical trial. Clin Implant Dent Relat Res 2020;22:497-506.

17. Linkevicius T, Apse P, Grybauskas S, et al. Reaction of crestal bone around implants depending on mucosal tissue thickness. A 1-year prospective clinical study. Stomatologija 2009;11:83-91.

18. Collaert B, De Bruyn H. Early loading of four or five Astra Tech fixtures with a fixed cross-arch restoration in the mandible. Clin Implant Dent Relat Res 2002;4:133-5.

19. Ata-Ali J, Peñarrocha-Oltra D, Candel-Marti E, et al. Oral rehabilitation with tilted dental implants: a metaanalysis. 
Med Oral Patol Oral Cir Bucal 2012;17:e582-7.

20. Hopp M, de Araújo Nobre M, Maló P. Comparison of marginal bone loss and implant success between axial and tilted implants in maxillary All-on-4 treatment concept rehabilitations after 5 years of follow-up. Clin Implant Dent Relat Res 2017;19:849-59.

21. Omori Y, Lang NP, Botticelli D, et al. Biological and mechanical complications of angulated abutments connected to fixed dental prostheses: A systematic review with meta-analysis. J Oral Rehabil 2020;47:101-11.

doi: 10.21037/fomm-21-64

Cite this article as: Bernabeu-Mira JC, Soto-Peñaloza D, Peñarrocha-Diago M, Peñarrocha-Oltra D. Influence of abutment characteristics on marginal bone level changes in immediate loading implant-supported full-arch fixed dental prostheses: a retrospective case series study with 1-year followup. Front Oral Maxillofac Med 2021;3:34.
22. Katafuchi M, Weinstein BF, Leroux BG, et al. Restoration contour is a risk indicator for peri-implantitis: A crosssectional radiographic analysis. J Clin Periodontol 2018;45:225-32.

23. Davies JE. Understanding peri-implant endosseous healing. J Dent Educ 2003;67:932-49.

24. Ting M, Tenaglia MS, Jones GH, et al. Surgical and Patient Factors Affecting Marginal Bone Levels Around Dental Implants: A Comprehensive Overview of Systematic Reviews. Implant Dent 2017;26:303-15. 